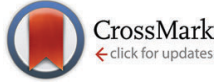

Cite this: Metallomics, 2015 7,66

Received 1st October 2014 Accepted 14th November 2014

DOI: $10.1039 / c 4 m t 00258 j$

www.rsc.org/metallomics

\section{Traumatic brain injury induces elevation of Co in the human brain}

\author{
Blaine R. Roberts, ${ }^{a}$ Dominic J. Hare, ${ }^{\text {ab }}$ Catriona A. McLean, ${ }^{c}$ Alison Conquest, ${ }^{d}$ \\ Monica Lind, ${ }^{a}$ Qiao-Xin Li, ${ }^{a}$ Ashley I. Bush, ${ }^{a}$ Colin L. Masters, ${ }^{a}$ \\ Maria-Christina Morganti-Kossmann ${ }^{d}$ and Tony Frugier*cde
}

Traumatic brain injury (TBI) is the most common cause of death and disability in young adults, yet the molecular mechanisms that follow TBI are poorly understood. We previously reported a perturbation in iron (Fe) levels following TBI. Here we report that the distribution of cobalt (Co) is modulated in post-mortem human brain following injury. We also investigated how the distribution of other biologically relevant elements changes in TBI. Cobalt is increased due to TBI while copper ( $\mathrm{Cu}$ ), magnesium (Mg), manganese $(\mathrm{Mn})$, phosphorus $(\mathrm{P})$, potassium $(\mathrm{K})$, rubidium $(\mathrm{Rb})$, selenium $(\mathrm{Se})$ and zinc $(\mathrm{Zn})$ remain unchanged. The elevated Co has important implications for positron emission tomography neuroimaging. This is the first demonstration of the accumulation of $\mathrm{Co}$ in injured tissue explaining the previous utility of ${ }^{55} \mathrm{Co}-\mathrm{PET}$ imaging in TBI.

Traumatic brain injury (TBI) is a major health and socioeconomic problem worldwide which according to the World Health Organization projection will become the major cause of death and disability by 2020 . Annually there are an estimated 10 million people affected by TBI. ${ }^{1}$ Repeated or moderate to severe TBI is suspected to be a risk factor for the development of Alzheimer's disease $^{2}$ and sporadic Parkinson's disease. ${ }^{3}$ In humans the molecular mechanisms leading to neurodegeneration and poor neurological outcome remain unclear.

Transition elements, although in trace amounts, are vital for biological function and for all facets of life. Approximately half of all enzymes are metalloenzymes. ${ }^{4}$ Zinc has been implicated as having a positive impact on the outcome of TBI in mouse models, ${ }^{5,6}$ but there is a lack of information on how metals

\footnotetext{
${ }^{a}$ The Florey Institute of Neuroscience and Mental Health, The University of Melbourne, Parkville, Victoria, Australia

${ }^{b}$ Elemental Bio-imaging Facility, University of Technology Sydney, Broadway, NSW, Australia

${ }^{c}$ Department of Anatomical Pathology, The Alfred Hospital, Melbourne, Victoria, Australia

${ }^{d}$ National Trauma Institute, The Alfred Hospital, Melbourne, Victoria, Australia

${ }^{e}$ Department of Pharmacology and Therapeutics, The University of Melbourne, Parkville Campus, Victoria 3031, Australia.E-mail: tony.frugier@unimelb.edu.au; Fax: +61 38344 0241; Tel: +6139035 7662
}

change as a result of TBI in humans, save for a recent report of iron (Fe) accumulation post-injury. ${ }^{7}$ In this study we analyze the level of cobalt $(\mathrm{Co})$, copper $(\mathrm{Cu})$, iron $(\mathrm{Fe})$, magnesium $(\mathrm{Mg})$, manganese $(\mathrm{Mn})$, phosphorus $(\mathrm{P})$, potassium $(\mathrm{K})$, rubidium $(\mathrm{Rb})$, selenium (Se) and zinc ( $\mathrm{Zn})$ in human brain tissue of patients who died from severe traumatic brain injury.

All procedures were conducted in accordance with the Australian National Health and Medical Research Council's National Statement on Ethical Conduct in Human Research (2007), the Victorian Human Tissue Act (1982), the National Code of Ethical Autopsy Practice (2002) and the Victorian Government policies and practices in relation to post-mortem.

Trauma brain samples from 27 individuals who died after closed head injury were obtained from the Australian Neurotrauma Tissue and Fluid Bank. Cases were aged between 17 and 78 years ( mean $=48$ years) and the causes of injury included motor vehicle accident, motorbike accident, nursing home accident, household accident, stair accident and falls. The post-mortem intervals varied between 33 and 129 hours (mean $=81$ hours). Patients were divided in 3 groups to compare the acute and delayed times after injury: 10 cases ( 8 males and 2 females) had survival time of less than 17 minutes, designated 'acute' group, when death occurred upon arrivals of the paramedics (cases 1-10); 8 cases (7 males and 1 female) were selected with a survival time between 30 minutes and 3 hours (mean $=1$ hour) and designated as 'early' group (cases 11-18); and 9 cases (7 males and 2 females) had survival time between 6 and 122 hours (mean = 43 hours) and designated 'late' group (cases 19-27). The late cohort also contains tissue from the same area on the non-injured (late-NI) side of the brain. The brain region analyzed was located in proximity of the injured tissue and was identified macroscopically by a neuropathologist (Prof. McLean). Control brain samples of 10 individuals, aged between 16 and 78 (mean $=56$ years), without brain injury or other neuropathology were obtained from the National Neural Tissue Resource Centre of Australia (cases 28-37). Clinical information and epidemiological details of all patients are described in Table 1.

Approximately $0.25 \mathrm{~g}$ of frozen tissue was allowed to thaw from $-80{ }^{\circ} \mathrm{C}$ on ice and then homogenized using a 
Table 1 Details of the 27 trauma and 10 control cases. Cases 1-10: cases with a survival time between 0 and 17 minutes; cases 11-18: cases with a survival time between 30 minutes and 3 hours; cases 19-27: cases with a survival time between 6 and 261 hours; cases 28-37: control cases. All brains were obtained at autopsy. $\mathrm{PMI}=$ post mortem interval (time between death and brain retrieval); $\mathrm{M}=$ male; $\mathrm{F}=$ female

\begin{tabular}{|c|c|c|c|c|c|c|}
\hline Case & Age & Sex & Cause of injury & PMI (h) & Cause of death & Survival time \\
\hline$\overline{1^{a}}$ & 51 & M & Motor vehicle accident & 60 & Brain + multiple injuries & $<17 \min$ \\
\hline $2^{a}$ & 63 & M & Household accident & 70 & Brain injury & $<17 \min$ \\
\hline $3^{a}$ & 27 & M & Suicide & 84 & Brain + multiple injuries & $<17$ min \\
\hline $4^{a}$ & 41 & M & Suicide & 96 & Brain + multiple injuries & $<17$ min \\
\hline $5^{a}$ & 57 & $\mathrm{~F}$ & Motor vehicle accident & 87 & Brain + multiple injuries & $<17$ min \\
\hline $6^{a}$ & 49 & M & Motor vehicle accident & 107 & Brain + multiple injuries & $<17$ min \\
\hline $7^{a}$ & 45 & M & Motor vehicle accident & 43 & Brain + multiple injuries & $<17 \min$ \\
\hline $8^{a}$ & 21 & M & Motor vehicle accident & 100 & Brain injury & $<17 \min$ \\
\hline $9^{a}$ & 41.3 & $\mathrm{M}$ & Aviation accident & 114 & Brain + multiple injuries & $<17 \min$ \\
\hline $10^{a}$ & 57.6 & $\mathrm{~F}$ & Motor vehicle accident & 97 & Brain injury & $<17 \min$ \\
\hline $11^{b}$ & 16.8 & M & Motor vehicle accident & 85 & Brain + multiple injuries & $<3 \mathrm{~h}$ \\
\hline $12^{b}$ & 78.7 & M & Household accident & 45 & Brain injury & $<3 \mathrm{~h}$ \\
\hline $13^{b}$ & 18.3 & M & Motor vehicle accident & 79 & Brain + multiple injuries & $<3 \mathrm{~h}$ \\
\hline $14^{b}$ & 34.7 & $\mathrm{M}$ & Motorbike accident & 66 & Brain + multiple injuries & $<3 \mathrm{~h}$ \\
\hline $15^{b}$ & 22.9 & $\mathrm{~F}$ & Motor vehicle accident & 108 & Brain + multiple injuries & $<3 \mathrm{~h}$ \\
\hline $16^{b}$ & 52.8 & M & Motorbike accident & 65 & Brain + multiple injuries & $<3 \mathrm{~h}$ \\
\hline $17^{b}$ & 19.6 & $\mathbf{M}$ & Suicide & 33 & Brain + multiple injuries & $<3 \mathrm{~h}$ \\
\hline $18^{b}$ & 59.8 & M & Motor vehicle accident & 71 & Brain + multiple injuries & $<3 \mathrm{~h}$ \\
\hline $19^{c}$ & 46.0 & M & Fall & 129 & Brain injury & $6 \mathrm{~h}$ \\
\hline $20^{c}$ & 56.3 & M & Motor vehicle accident & 65 & Brain injury & $8 \mathrm{~h}$ \\
\hline $21^{c}$ & 64.6 & M & Fall & 61 & Brain injury & $8 \mathrm{~h}$ \\
\hline $22^{c}$ & 75.9 & M & Staircase fall & 89 & Brain injury & $10 \mathrm{~h}$ \\
\hline $23^{c}$ & 59.6 & $\mathrm{~F}$ & Motor vehicle accident & 80 & Brain injury & $35 \mathrm{~h}$ \\
\hline $24^{c}$ & 61.7 & M & Fall & 40 & Brain injury & $93 \mathrm{~h}$ \\
\hline $25^{c}$ & 38.9 & $\mathrm{~F}$ & Staircase fall & 101 & Brain injury & $122 \mathrm{~h}$ \\
\hline $26^{c}$ & 70.9 & M & Motor vehicle accident & 114 & Brain injury & $76 \mathrm{~h}$ \\
\hline $27^{c}$ & 73.7 & M & Fall & 91 & Brain injury & $29 \mathrm{~h}$ \\
\hline $28^{d}$ & 16 & M & - & - & Suicide by hanging & - \\
\hline $29^{d}$ & 48.7 & $\mathrm{M}$ & - & 50 & Cardiac failure & - \\
\hline $30^{d}$ & 51.6 & M & - & 64 & Asthma & - \\
\hline $31^{d}$ & 52.3 & $\mathrm{M}$ & - & 52 & Cardiomyopathy & - \\
\hline $32^{d}$ & 59.6 & M & - & 43 & Pulmonary embolism & - \\
\hline $33^{d}$ & 64.1 & M & - & 24 & Ischaemic heart disease & - \\
\hline $34^{d}$ & 66.9 & M & - & 10 & Pneumonia & - \\
\hline $35^{d}$ & 64.4 & M & - & 24 & Pulmonary embolism & - \\
\hline $36^{d}$ & 77.5 & M & - & 53 & Myocardial infarction & - \\
\hline $37^{d}$ & 60 & $\mathrm{~F}$ & - & 48 & Myocardial infarction & - \\
\hline
\end{tabular}

BioMasher (Omni International). Tissue was placed in the BioMasher, the plunger was inserted and then the apparatus was centrifuged at $10000 \mathrm{rpm}$ with a benchtop centrifuge. After centrifugation Tris buffer saline (TBS, $50 \mathrm{mM}$ Tris $\mathrm{pH}$ 8.0, $150 \mathrm{mM} \mathrm{NaCl}$ ) containing EDTA free protease inhibitors (Roche) was added at a ratio of $1: 4(\mathrm{w} / \mathrm{v})$. The sample was centrifuged at $175000 \mathrm{~g}$ for 30 minutes at $4{ }^{\circ} \mathrm{C}$. The TBS supernatant was collected and stored at $-80{ }^{\circ} \mathrm{C}$ before analysis. The resulting pellet was washed with a volume of TBS equal to the amount used for homogenization and centrifuged for 15 minutes at $175000 \mathrm{~g}$ at $4{ }^{\circ} \mathrm{C}$. The TBS wash supernatant was removed and the pellet was resuspended in $7 \mathrm{M}$ urea $2 \mathrm{M}$ thiourea $4 \%$ CHAPS $30 \mathrm{mM}$ bicine $\mathrm{pH} 8.5$ and centrifuged as before. The resulting pellet was then incubated with $70 \%$ formic acid for 16 hours at room temperature before being centrifuged at $16000 \mathrm{~g}$ for 30 minutes.

Inductively coupled plasma mass spectrometry (ICP-MS) was used to determine the quantity of $\mathrm{Co}, \mathrm{Cu}, \mathrm{Fe}, \mathrm{Mg}, \mathrm{Mn}, \mathrm{P}, \mathrm{K}, \mathrm{Rb}$,
Se and $\mathrm{Zn}$ in the TBS soluble, membrane and formic acid extracted homogenates. Supernatants were diluted 1:15 with $1 \%$ nitric acid (Suparpur, Merck). Measurements were made using an Agilent 7700 series ICP-MS instrument under routine multi-element operating conditions using a helium collision gas cell. The instrument was calibrated using 0, 5, 10, 50 and $100 \mathrm{ppb}$ of certified multi-element ICP-MS standard calibration solutions (ICP-MS-CAL2-1, ICP-MS-CAL-3 and ICP-MS-CAL-4, Accustandard) for a range of elements. We used a certified internal standard solution containing $200 \mathrm{ppb}$ of yttrium $\left({ }^{89} \mathrm{Y}\right)$ as an internal control (ICP-MS-IS-MIX1-1, Accustandard). The sample was introduced via the automated liquid sampler (Agilent) using a peristaltic pump at a flow rate of $0.4 \mathrm{~mL} \mathrm{~min}^{-1}$.

Statistical analysis was performed using SigmaStat (SysStat, San Jose, CA), Prism 5.0 (GraphPad, La Jolla, CA) and SPSS software (SPSS Inc., Chicago, IL). Kolmogorov-Smirnov test (with Lilliefors' correction) was used to test data for normality within each group and values were transformed by natural 
1
0
0

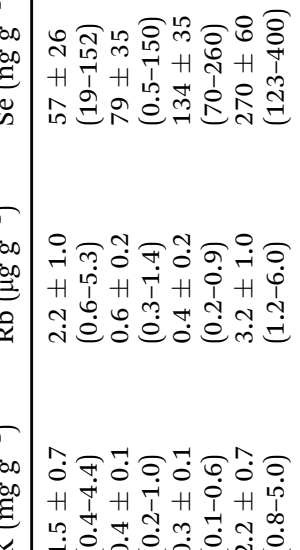

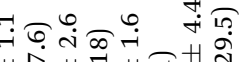
$\infty$ m. a)

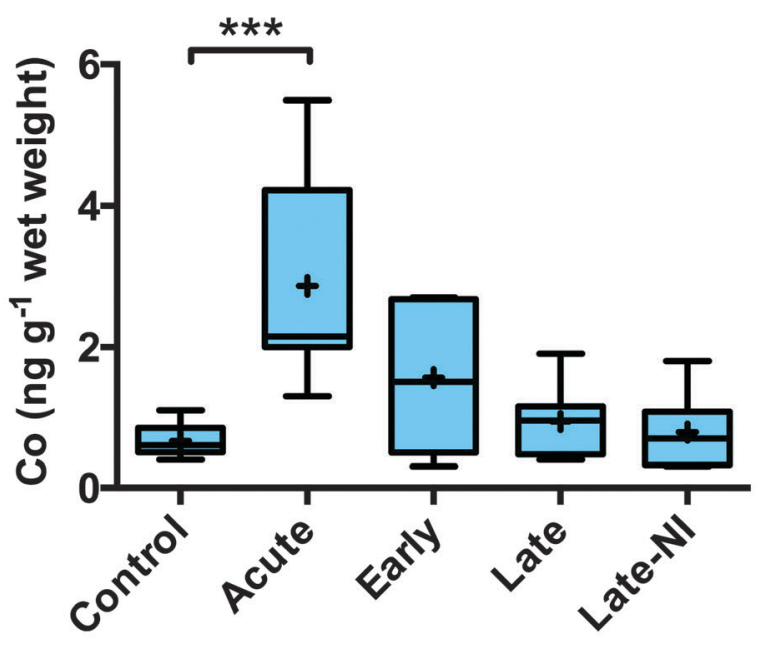

b)

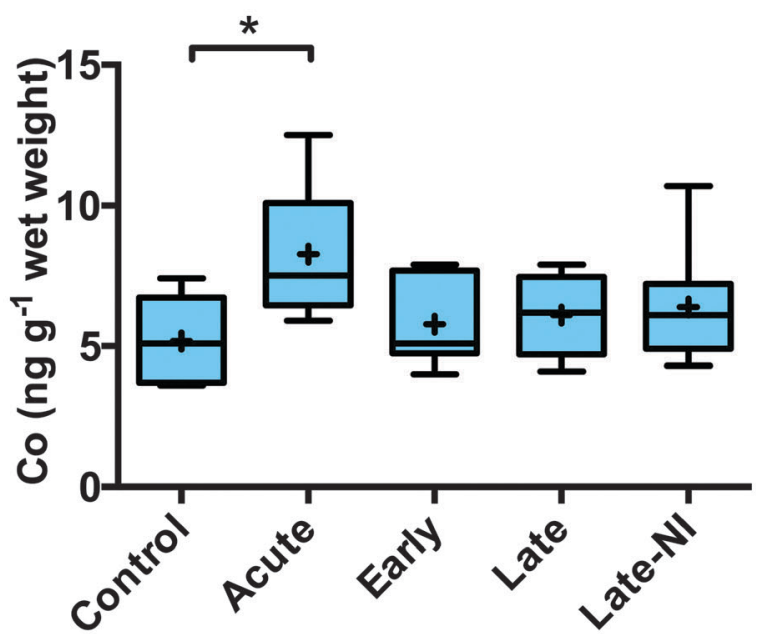

Fig. 1 Elevated levels of $\mathrm{Co}$ in the human brain following TBI as measured by ICP-MS. (a) Co is significantly elevated in the acute TBI cases in the TBS soluble extracted material compared to all other groups (***Tukey posthoc test $p<0.001)$ and (b) in the total Co levels calculated as the sum of soluble, membrane and formic acid extracted Co is also significantly elevated but to a lesser extent ( ${ }^{*}$ Tukey post-hoc test $p<0.05$ ). Boxes represent interquartile range; error bars represent minimum and maximum values; + represents mean and line represents median. 

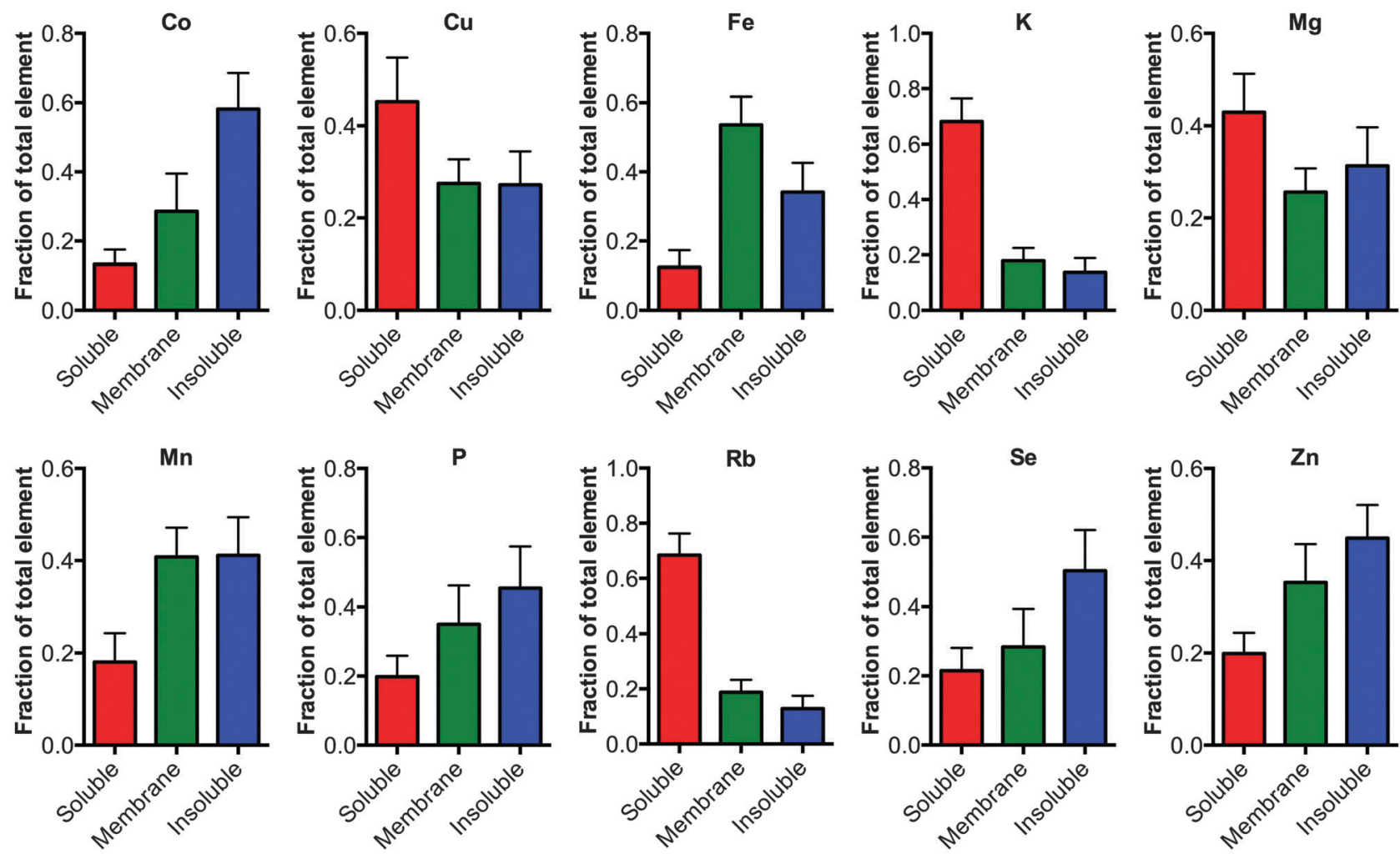

Fig. 2 Distribution of elements in the cellular fractions. The elements $\mathrm{Co}, \mathrm{Cu}, \mathrm{Fe}, \mathrm{Mg}, \mathrm{Mn}, \mathrm{P}, \mathrm{K}, \mathrm{Rb}$, Se and $\mathrm{Zn}$ were measured in the soluble, membrane and formic acid fractions using ICP-MS, no significant changes were observed between the tissue from TBI and controls (one-way ANOVA) except for Co as noted in Fig. 1. The fraction of each element in the respective pool is graphed (mean \pm 1 standard deviation). As expected elements that are truly fee ions such as $\mathrm{Rb}$ and $\mathrm{K}$ are mostly distributed in the soluble phase.

membrane or FA fractions (Table 2). Although the elevation in Co remained significantly elevated in the total (Fig. 1b, [total] = [soluble + membrane $+\mathrm{FA}]$ ) the signal to noise was much greater due to the addition of the membrane and FA fractions. The elevation of Co returned to baseline 3 hours post-injury.

Finally, the fractionation protocol allowed a more detail analysis about how the elements are distributed in the tissue (Fig. 2). Analyzing the proportion of an element in each fraction showed that elements $\mathrm{K}$ and $\mathrm{Rb}$ are greater than $70 \%$ associated with the soluble extracted material consistent with these elements being free ions. ${ }^{11}$ Alternatively, elements largely associated to membrane bound proteins, such as $\mathrm{Fe}$, had greater than $80 \%$ of the element associated with the membranous pellet (membrane plus FA fraction) consistent with Fe being a cofactor for membrane associated proteins involved in the electron transport chain, for example.

Calcium (Ca) overload and inflammatory process are both attributed to the resulting neuronal death. Co is used as a surrogate marker of $\mathrm{Ca}$ accumulation in degenerating neurons. ${ }^{12}$ Radioisotopes of Co have been successfully used to detect ischemic damage, extravasation or inflammation in several neurodegenerative pathologies. ${ }^{13-15}$ This is the first study to demonstrate that TBI induces the specific uptake of in situ Co into brain tissue. Cobalt is predominantly found as cobalamin (vitamin $\mathrm{B}_{12}$ ), which is used as a cofactor for methyl transfer reactions that are vital for DNA synthesis and fatty acid synthesis. Alternatively, Co is also utilized in a vitamin $B_{12}$ independent fashion in the enzyme methionine aminopeptidase $2,{ }^{16}$ which removes the N-terminal methionine of newly synthesized proteins and plays a vital role in the angiogenesis of blood vessels and as such is a target of anticancer angiogenesis compounds. Long-term hypoxia in mice has been shown to both elevate brain Co levels and increase activity of vitamin $\mathrm{B}_{12} \cdot{ }^{17}$ Previous positron emission tomography studies have used ${ }^{55} \mathrm{CoCl}_{2}$ to detect areas of ischemic damage, suggesting that the observed increase in Co in acute patients may also be due to an influx of non-vitamin $B_{12}$ Co. Additionally, the cellular fractionation of the tissue into soluble and membrane pools demonstrate that the increased Co is due to an actual accumulation of Co, likely from the blood. There is an emerging role for cobalamin in regulating the production of growth factors and cytokines in the $\mathrm{CNS}^{18}$ and this may be related to the increased uptake of this element in response to TBI. Vitamin $B_{12}$ and its cobalamin products, ${ }^{19}$ specifically the thiolato-derivatives ${ }^{20}$ have also been shown to possess potent antioxidant properties in vitro, which may explain the rapid influx of Co to brain regions under increased oxidative stress, as is the case following acute TBI. ${ }^{21}$

\section{Acknowledgements}

This study was supported by the Victorian Neurotrauma Initiative. Brain tissues were obtained from the Victorian Brain Bank Network, supported by The National Trauma Research Institute, 
The University of Melbourne, The Florey Institute of Neuroscience and Mental Health, The Victorian Institute of Forensic Medicine and funded by the Victorian Neurotrauma Initiative, Neurosciences Australia, the National Health \& Medical Research Council of Australia and the Victorian Government's Operational Infrastructure Support Program.

\section{Notes and references}

1 A. A. Hyder, C. A. Wunderlich, P. Puvanachandra, G. Gururaj and O. C. Kobusingye, NeuroRehabilitation, 2007, 22, 341-353.

2 V. E. Johnson, W. Stewart and D. H. Smith, Nat. Rev. Neurosci., 2010, 11, 361-370.

3 S. M. Goldman, C. M. Tanner, D. Oakes, G. S. Bhudhikanok, A. Gupta and J. W. Langston, Ann. Neurol., 2006, 60, 65-72.

4 K. J. Waldron, J. C. Rutherford, D. Ford and N. J. Robinson, Nature, 2009, 460, 823-830.

5 B. Young, L. Ott, E. Kasarskis, R. Rapp, K. Moles, R. J. Dempsey, P. A. Tibbs, R. Kryscio and C. McClain, J. Neurotrauma, 1996, 13, 25-34.

6 P. Doering, M. Stoltenberg, M. Penkowa, J. Rungby, A. Larsen and G. Danscher, PLoS One, 2010, 5, e10131.

7 S. Ayton, M. Zhang, B. R. Roberts, L. Q. Lam, M. Lind, C. McLean, A. I. Bush, T. Frugier, P. J. Crack and J. A. Duce, Free Radical Biol. Med., 2014, 69, 331-337.

8 R. M. Parr and D. M. Taylor, Biochem. J., 1964, 91, 424-431. 9 M. T. Rajan, K. S. Jagannatha Rao, B. M. Mamatha, R. V. Rao, P. Shanmugavelu, R. B. Menon and M. V. Pavithran, J. Neurol. Sci., 1997, 146, 153-166.
10 N. A. Larsen, H. Pakkenberg, E. Damsgaard and K. Heydorn, J. Neurol. Sci., 1979, 42, 407-416.

11 A. S. Relman, Yale J. Biol. Med., 1956, 29, 248-262.

12 N. E. Andersen, J. Gyring, A. J. Hansen, H. Laursen and B. K. Siesjö, J. Cereb. Blood Flow Metab., 1989, 9, 381-387.

13 H. M. Jansen, J. van der Naalt, A. H. van Zomeren, A. M. Paans, L. Veenma-van der Duin, J. M. Hew, J. Pruim, J. M. Minderhoud and J. Korf, J. Neurol., Neurosurg. Psychiatry, 1996, 60, 221-224.

14 J. De Reuck, P. Santens, K. Strijckmans and I. Lemahieu, J. Neurol. Sci., 2001, 193, 1-6.

15 H. M. Jansen, J. Pruim, A. M. vd Vliet, A. M. Paans, J. M. Hew, E. J. Franssen, B. M. de Jong, J. G. Kosterink, R. Haaxma and J. Korf, J. Nucl. Med., 1994, 35, 456-460.

16 Y. Hu, F. Vanhaecke, L. Moens, R. Dams, P. del Castilho and J. Japenga, Anal. Chim. Acta, 1998, 373, 95-105.

17 S. C. Veasey, J. Lear, Y. Zhu, J. B. Grinspan, D. J. Hare, S. Wang, D. Bunch, P. A. Doble and S. R. Robinson, Sleep, 2013, 36, 1471-1481.

18 G. Scalabrino, J. Neurochem., 2009, 111, 1309-1326.

19 E. S. Moreira, N. E. Brasch and J. Yun, Free Radical Biol. Med., 2011, 51, 876-883.

20 C. S. Birch, N. E. Brasch, A. McCaddon and J. H. Williams, Free Radical Biol. Med., 2009, 47, 184-188.

21 V. A. Tyurin, Y. Y. Tyurina, G. G. Borisenko, T. V. Sokolova, V. B. Ritov, P. J. Quinn, M. Rose, P. Kochanek, S. H. Graham and V. E. Kagan, J. Neurochem., 2000, 75, 2178-2189. 


\section{University Library}

\section{- M M N E R VA A gateway to Melbourne's research publications}

Minerva Access is the Institutional Repository of The University of Melbourne

Author/s:

Roberts, BR;Hare, DJ;McLean, CA;Conquest, A;Lind, M;Li, Q-X;Bush, Al;Masters, CL;Morganti-Kossmann, M-C;Frugier, T

Title:

Traumatic brain injury induces elevation of $\mathrm{Co}$ in the human brain

Date:

2015-01-01

Citation:

Roberts, B. R., Hare, D. J., McLean, C. A., Conquest, A., Lind, M., Li, Q. -X., Bush, A. I., Masters, C. L., Morganti-Kossmann, M. -C. \& Frugier, T. (2015). Traumatic brain injury induces elevation of Co in the human brain. METALLOMICS, 7 (1), pp.124-128. https:// doi.org/10.1039/c4mt00258j.

Persistent Link:

http://hdl.handle.net/11343/58818 